\title{
A Comparative Study on English and Chinese Kinship Terms and Their Translation Strategies
}

\author{
Chen Chen \\ School of Foreign Languages, Shanxi Normal University, Linfen, China
}

\begin{abstract}
As an important part of addressing forms, kinship terms are frequently used in our daily life. Both Chinese and English languages have their unique cultural background, which determines the significant differences between English and Chinese kinship systems. This paper first makes a comparative analysis and a systematic induction of the English and Chinese kinship terms, then reveal the causes that the differences between the two kinship systems result from, and finally attempts to explores three translation methods of Chinese and English kinship terms, which will attach much more significance to cross-cultural communication as well.
\end{abstract}

Index Terms—English and Chinese kinship terms, differences, causes, translation strategies

\section{INTRODUCTION}

Kinship terms are quite common linguistic phenomena in human daily life across cultures. They are the prelude to personal association and their proper use is the prerequisite to achieve the aim of personal contact. They also play an important role in intercultural communication. In many circumstances, kinship terms are the very first message conveyed to the addressee. At times, a simple kinship term can take the place of a long sentence in conveying a profound meaning.

Kinship terms are involved in any language, but they are different in different languages. Each nation has its own unique kinship system unique cultural background. Kinship terms are important as well as frequent in everyday social interactions all over the world. And appropriate addressing behavior is extremely important for the establishment and maintenance of interpersonal relationships. The study of kinship terms has attracted great attention from scholars both at home and abroad. The study of kinship terms is not only a linguistic problem, but also a cultural problem. At present, the comparative study of English and Chinese kinship terms is not a new topic. A lot of research has been done on this topic by predecessors. The major research perspectives are as follows: systematic perspective, including Li Mingjie's (1997) definition, classification and evolution of kinship terms; Liu Jinling, Lin Li(2004), Chen Jianmin's (1990) sociolinguistic perspective, including the relationship between social and cultural factors and appellation terms. After reviewing considerable literature on kinship termiology, it is found that most researchers have also made great efforts to show the differences between English and Chinese kinship terms, the causes for the differences and how to better realize the translation between English and Chinese kinship terms. In this study, the author attempts to put forward some opinions on the basis of previous studies. Specifically speaking, the author illustrates the differences between English and Chinese kinship terms with explicit diagrams, reveals the causes, and finally puts forward three translation methods based on corpus.

\section{CONTRAST OF KinSHIP TERMS}

Both English and Chinese have their own kinship terms system and these two systems play their respective roles in the society. There are both similarities and differences between English and Chinese kinship terms. On the one hand, some basic kinship terms have the same meaning in both languages. On the other hand, most of their kinship terms are different from each other, because they have different cultures and language forms.

The similarities between the two kinship systems are as follows:

English and Chinese kinship terms have something in common. Both of them distinguish between generations, e.g., the difference between a parent and a child, and they also distinguish between sexes, e.g., the difference between a brother and a mother. Moreover, these two kinship systems make a distinction between kinship terms by blood and marriage. For instance, mother-in-law and mother differ in that mother-in-law is a relative by marriage but mother is a kinship term by blood.

By contrast, Chinese kinship system is considered as the most complicated of all kinship systems. The differences between English and Chinese kinship terms can be explicitly shown as the following table. 
TABLE I

\begin{tabular}{|c|c|c|}
\hline Relation to Ego & Chinese kinship term & English kinship term \\
\hline Paternal grandfather & 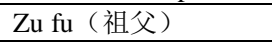 & \multirow[t]{2}{*}{ Grandfather } \\
\hline Maternal grandfather & Wai zu fu（外祖父） & \\
\hline Paternal grandmother & 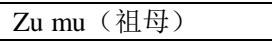 & \multirow[t]{2}{*}{ Grandmother } \\
\hline Maternal grandmother & Wai zu mu（外祖母） & \\
\hline Father & Fu qin（父亲） & Father \\
\hline Mother & Mu qin（母亲） & Mother \\
\hline Son & Er zi（儿子） & Son \\
\hline Daughter & Nu er（女儿） & Daughter \\
\hline Son's son & Sun zi（孙子） & \multirow[t]{2}{*}{ Grandson } \\
\hline Daughter's son & Wai sun zi（外孙子） & \\
\hline Son's daughter & Sun nu（孙女） & \multirow[t]{2}{*}{ Granddaughter } \\
\hline Daughter's daughter & Wai sun nu（外孙女） & \\
\hline
\end{tabular}

TABLE II

\begin{tabular}{|c|c|c|c|}
\hline \multirow{2}{*}{\multicolumn{2}{|c|}{$\begin{array}{l}\text { Relation to ego } \\
\text { Father's elder brother }\end{array}$}} & Chinese kinship term & English kinship term \\
\hline & & Bo fu（伯父） & \multirow[t]{5}{*}{ Uncle } \\
\hline \multicolumn{2}{|c|}{ Father's younger brother } & shu fu（叔父） & \\
\hline \multicolumn{2}{|c|}{ Father's sister's husband } & Gu fu（姑父） & \\
\hline \multicolumn{2}{|l|}{ Mother's brother } & Jiu fu（舅父） & \\
\hline \multicolumn{2}{|c|}{ Mother's sister's husband } & Yi fu（姨父） & \\
\hline \multicolumn{2}{|c|}{ Father's elder brother's wife } & Bo mu（伯母） & \multirow[t]{5}{*}{ Aunt } \\
\hline \multicolumn{2}{|c|}{ Father's younger brother's wife } & Shen mu（婶母） & \\
\hline \multicolumn{2}{|c|}{ Father's sister } & Gu mu（姑母） & \\
\hline \multicolumn{2}{|l|}{ Mother's brother's wife } & Jiu mu（舅母） & \\
\hline \multicolumn{2}{|l|}{ Mother's sister } & Yi ma（姨妈） & \\
\hline \multicolumn{4}{|c|}{ TABLE III } \\
\hline \multicolumn{2}{|l|}{ Relation to ego } & Chinese kinship term & English kinship term \\
\hline \multicolumn{2}{|l|}{ Elder brother } & Ge ge（哥哥） & Brother \\
\hline Younger brother & Di d & & \\
\hline Elder sister's husband & Jie fi & & Brother-in-law \\
\hline Younger sister's huaband & Mei & & \\
\hline Elder sister & Jie ji & & Sister \\
\hline younger sister & Mei & & \\
\hline Elder brother's wife & Sao & & Sister-in-law \\
\hline Younger brother's wife & Di $\mathrm{m}$ & & \\
\hline & & TABLE IV & \\
\hline Relation to ego & Age to eg & \begin{tabular}{l|l} 
Chinese kinship term \\
\end{tabular} & English kinship term \\
\hline Father's brother's son & Elder & Tang ge（堂哥） & Cousin \\
\hline & Younger & Tang di（堂弟） & \\
\hline Mother's brother's son and & Elder & Yi biao ge（姨表哥） & \\
\hline sister's son & Younger & Yi biao di（姨表弟） & \\
\hline Father's sister's son & Elder & Gu biao ge（姑表哥） & Cousin \\
\hline & Younger & Gu biao di（姑表弟） & \\
\hline Father's brother's daughter & Elder & Tang jie（堂姐） & \\
\hline & Younger & Tang mei（堂妹） & \\
\hline Father's sister's daughter & Elder & Gu biao jie（姑表姐） & \\
\hline & Younger & Gu biao mei（姑表妹） & \\
\hline Mother's brother's and & Elder & Yi biao jie（姨表姐） & \\
\hline sister's daughter & Younger & Yi biao mei（姨表妹） & \\
\hline
\end{tabular}

TABLE V

\begin{tabular}{l|l|l}
\hline Relation to ego & Chinese kinship term & English kinship term \\
\hline Brother's son & Zhi zi (侄子) & Nephew \\
\cline { 1 - 2 } Sister's son & Wai sheng (外甥) & \\
\hline Brother's daughter & Zhi nu（侄女） & \multirow{2}{*}{ Niece } \\
\cline { 1 - 2 } Sister's daughter & Wai sheng nu（外甥女） & \\
\hline
\end{tabular}

The differences between English and Chinese kinship terms can be summarized as follows:

Firstly, contrast of elder-younger relations and seniority order in the clan.

In Chinese kinship system, age is very important. Specific terms can be used to show their different ages. A typical example is the kinship terms $b o f u$ (伯父) and $s h u f u$ （叔父）. The former is used to address father's elder brother, while 
the latter is for father's younger brother. Chinese could hardly contain the mistake of elder-younger relations and seniority order. For example, if one's father has more than one elder and younger brothers, he could call them: first bo fu （大伯父）, second bo fu （二伯父）, or first shu shu(大叔), second shu shu(二叔) and so on to exhibit their order.

Unlike the Chinese language, age is not a criterion to distinguish personal relationships or kinship terms in English. In English, there are only two kinship terms for siblings brother and sister. They usually say "she is my sister", whether she is younger or elder than them. Only when they say "she is my younger or elder sister", they want to emphasize the age.

Secondly, contrast of blood relation and relations by marriage.

Blood relation means a person related by birth rather than by marriage. Blood Relation Rule reflects that the kinship classifications require different address forms to kin on mother's side. Marriage Relation Rule requires using two address systems to the members of the same clan and relation by marriage. There are too many address words in blood relation and relation by marriage in Chinese kinship terms. For example yifu（姨父）（husband of mother's sister） belong to relation by marriage. While yi ma(姨妈) (mother's sister) belong to blood relation. From these examples, we can see Chinese complicated blood relation and relation by marriage. Chinese kinship is patriarchal, because China is a patriarchy society; but English is not.

Chinese think that the differences between paternal and maternal relations are very important. The differences mean a lot to Chinese people and the relationships, near or distant, inside or outside, between relatives. Ancient China was based on patriarchal descent, which refers to descent traced exclusively through the male line for purpose of group membership. So there are different terms for one's paternal and maternal relations in China. For example, in China, paternal grandfather is called $z u f u$ (祖父), while maternal grandfather is called wai zu fu(外祖父). Wai in China means “distant" or "outside". The terms for grandchildren are the same with them. Usually, paternal relations are more powerful than maternal relations in Chinese family structure.

For English people, the difference between paternal and maternal is not clear. Thus father's father and mother's father are both grandfathers. Uncle is for both father's brother and mother's brother. In English, blood relation and relation by marriage are very simple class. Therefore, it's hard to understand the relation between various relatives and address in English countries.

\section{CAuse Analysis}

English and Chinese kinship terms system have some differences. English kinship system is relatively simple. By contrast, Chinese kinship system is more complicated. The reasons for the differences can be summarized as follows:

Firstly, Chinese kinship system lays much emphasis on patrilineality, and it is agnatic. However, English one is not.

Chinese people hold that consanguineous relations are much more important than affinal relations, which is evidently reflected by kinship terms. In Chinese culture, the difference between “close”(亲) and “distant”( 疏) is taken seriously by Chinese people. Naturally, maternal lineages are less closer than paternal ones. It is well-known that the patriarchal clan system is a typical important political system in ancient feudal society of China. Its characteristics can be summarized as follows: the patriarchal clan organization and the state organization are united, and the patriarchal clan hierarchy and the political hierarchy are identical. This system began in the Xia Dynasty and had great impact on later feudal dynasties. According to the patriarchal clan system of the Zhou Dynasty, the clan was divided into large clan and small clan. The large clan and small clan are provided with relativity, and the ordinary people's families were greatly affected by the system, which also reflected the strict concept of hierarchy. This patriarchal structure was maintained by blood and marriage. Although China has long been divorced from feudal society, the influence of patriarchal clan system is deep-rooted and far-reaching.

The core of patriarchal clan system is primogeniture, which is directly related to the patriarchal clan system. The ancient Chinese society is male-dominated. The most typical example is that the ancient emperors were male except $\mathrm{Wu}$ Zetian(an female emperor in ancient China). Hence, it is not surprising that maternal lineages are less"closer" than paternal ones in China now. Normally, father's brother's son or daughter, which represents kinship on father's side, is labelled “tang(堂)”, such as “Tang ge/di(堂哥/弟)”, while mother's brother's son or daughter, being maternal lineages, which represents kinship on mother's side, is labelled “biao(表)”, such as “Biao ge/di(表哥/弟)”. Whereas in English culture, people generally don't distinguish between paternal and maternal lineages, affinal and consanguineous relations. Thus, people from English-speaking countries even would not care whether an "uncle"is on father's side or mother's side in daily life.

Secondly, differences in economic factor.

China has experienced more than two thousand years of feudal society, while the western society has generally experienced a shorter feudal period, such as Britain's feudal history of only five hundred years. China's long-term feudal social formation had a multidimensional, far-reaching and even deep-rooted influence on the whole society at that time. On the contrary, in Western society, the capitalist system replaced the feudal system very early, which made British and American cultures originating from ancient Greece and Rome attach more importance to economic activities such as commerce, frequent immigration, family ties and so on.

In ancient Chinese feudal society, feudal land ownership was the major feudal land system. The forms of feudal land 
ownership vary in different periods. Land was the main means of production in feudal society. The landlord class held the vast majority of the land, and the peasants had only a small amount of land. Under this system, in order to survive, the peasants had to depend on the land on which they live. They were bound or stuck on their own land, with little mobility. In addition, the policy of emphasizing agriculture and restraining commerce in ancient China was adopted. At that time, the self-sufficient small-scale peasant economy was prevailing in the society. This situation determines that their relatives network is also very centralized, they have frequent contacts, and generations live here. Consequently, the peasants attach great importance to the family. For the need of communication with relatives, it is necessary to make the relationship between relatives very clear and definite. In western society, the vast majority of countries experienced a very short period of feudal society and turned to stoccapitalist society. The corresponding economic form was quite different from that of China at that time. It was based on private ownership. For example, in the enclosure movement of England in history, the new bourgeoisie and the new aristocracy drove peasants away from their land, and they were deprived of land-use right and ownership of land, and the occupied land was enclosed and turned into pasture. In a word, the economic form under capitalism separated them from the land earlier and formed a liberalized economic form. Hence, their urbanization process was much faster than that of China. We all know that, by comparison, people in cities pay less attention to kinship. Besides that, the western society, being adventurous, always attached great importance to overseas activities, which made the population more mobile. Such situation is not conducive to the formation of a more stable and complex kinship network.

Thirdly, differences in culture.

The differences between Chinese and English kinship terms reflect two different cultures. Chinese people lays much emphasis on "respect for seniority". However, in English culture, the descendant is allowed to call the elderly by name, which is often seen on TV, and children can perform intimacy in the way of calling the elderly by name. By contrast, in Chinese culture, normally, the descendant would not call the elderly by name for calling the elderly by name is considered an impolite behavior against the traditional value and morality. Thus, various precise kinship terms are indispensable in addressing in Chinese society.

China attached much importance to etiquette in the past dynasties, and the kinship system was an indispensable part of etiquette and an important reflection of it. For example, $\mathrm{Li} \mathrm{Ji}$, an important collection of rules and regulations in ancient China, mainly recorded the ritual system of Pre-Qin Dynasty, which embodied the philosophical, educational, political and aesthetic thoughts of Confucianism in Pre-Qin Dynasty. Another typical example was the establishment of ceremonial officers in ancient China, which was an important part of the six ministries of officials, which showed the importance attached to etiquette by the society at that time. Kinship terms have a diachronic evolution process, which can be studied from a diachronic perspective. The main reason why ancient China attached importance to etiquette system was the strict hierarchy in Chinese feudal society. Thus, in Chinese kinship system, many aspects were taken into consideration, such as gender, order of age and age, blood affinity and in-laws, internal clan or external clan, which were closely related to the worship of courtesy in ancient times.

Liang Zhangju, Zheng Zhen (1996) argued that Zhongbiao, both inside and outside. Father's sister's son is an external brother, mother's brother' son is an internal brother, so it is known as the cousin. This utterance elaborated the kinship terms between the two types of sons mentioned above, which indicated that people in ancient China began to make the distinction on whether being blood relatives of father's sister's son or not.

Fourthly, differences in family structures.

In China, the dominant type of family is extended family while in the West nuclear family. An extended family refers to a family consisting two or more generations of the same family sharing a common household and economic resource. Accordingly, a detailed division in kinship terms according to generation, age, and sex was required for people to address and distinguish different family members. In contrast, a nuclear family refers to a group consisting of parents and their unmarried children who live far away from other relatives. In western culture, people tend to live apart from their parents as soon as they get married because they uphold self-reliance, freedom and independence under the influence of individualism. So the overall generality of the English kinship terms reflects the much simpler and looser kinship relations in Western society.

\section{TRAnslation Method Of Chinese KINSHIP TERMS}

When carrying out the translation between two languages, we should consider not only the transformation of linguistic forms, but also the cultural differences between the two languages. Most of the kinship terms in English and Chinese are unequal, which is caused by different cultural backgrounds. Therefore, when translating kinship terms, it is necessary to take into account the different cultures of the two languages, so as to achieve the maximum meaning equivalence between the source language and the target language.

Next, the paper takes the classical translation of kinship terms in A Dream of Red Mansions as a case study to analyze some skills in translating Chinese kinship terms into English ones.

\section{A. Explanation}

The explanation method can be defined like this: it is mainly used to further explain the kinship appellation to show a clearer and more precise relationship between the characters to the readers. Therefore, the translation work should be 
based on the reader's point of view and the target language.

Example: 贾母......说: “你替我告诉他（指林黛玉）的阴灵: “并不是我忍心不来送你, 只为有了个亲疏。你 是我的外孙女儿, 是亲的了; 与宝玉比起来, 可是宝玉比你更亲些。”

Translation by Yang: The old lady instructed: The Tell her spirit from me, it's not because I'm heartless that I'm not coming to see you off, but there is someone closer here whom I have to see to. As my daughter's daughter you are dear to me; but Pao-yu is closer to me even than you.

From Jia Mu's words, we can see that she strictly distinguishes between clan and foreign clan. Baoyu is the grandson of Jia $\mathrm{Mu}$ and Daiyu is the granddaughter of Jia Mu. It is obvious that Jia Mu has different degrees of familiarity between them. In Yang's translation, he further explains the identity of Lin Daiyu, her granddaughter: daughter's daughter. Such a translation makes the relationship between Jia Mu and Lin Daiyu much clearer.

\section{B. Generalization (or Induction)}

Induction can be used when a clear relationship between characters is not required in the context.

Example: 贾母命两个老嬤嬤带黛玉去见两个舅舅去。

Translation: And the lady Downger ordered two nurses to take Tai Yu to see her two uncles.

Example: And the lady Downger ordered two nurses to take Tai Yu to see her two uncles.

\section{Notation}

The notation method can be defined like this: When doing the Chinese-English translation, the family name of the corresponding person should be added to the kinship term or the name should be added directly, so as to show readers a clearer relationship between characters.

Example: 凤姐说道: “刚才我到宝兄弟屋里, 我听见好几个人笑。我只道是谁, 巴者窗户眼儿一瞧, 原来宝 妹妹坐在炕沿上, 宝兄弟站在地下, 宝兄弟拉着宝妹妹的袖子, 口口声声只叫: “宝姐姐!你为什么不说话了?’”

Translation by Hawkes: Xi-feng began again: Just mow, I was passing through Cousin Bao-yu's apartment when I heard the sound of laughter coming from inside, and wondering who it could be, I took a peep through a little hole in the paper easement. There was Cousin Chai sitting on the edge of the kang, with Pao-Yu standing in front of her, holding her sleeve and imploring her, Oh, Coz! Why won't you speak to me?'”

There are many words such as "Bao Brother" and "Lin Sister" in A Dream of Red Mansions. Thus, the translation method of notation is also frequently used in Chinese-English translation, which would show readers a clearer relationship between characters.

\section{IMPLICATION AND APPLICATION IN ENGLISH TEACHING AND LEARNING}

Kinship term is a key and subtle component in daily communication. So the study of it can provide some implications for foreign language teaching. To most English teachers and English learners the study and the use of kinship terms are such a small matter that they don't pay much attention to them. But the proper use of English kinship terms in cross-cultural communication $s$ is much more difficult than what people may think.

In reality, foreign language learners would be affected by their mother tongues, which is inevitable in using a foreign language. Naturally, learners of different languages and cultures may have some difficulties in communicating with each other. On account of cultural differences, the same words or expressions may not mean the same things in different languages. A harmless statement may cause displeasure or misunderstanding. Similarly, a inappropriate question may bring about people's laughter.

To sum up, having a good command of the language of English means merely mastering the pronunciation, grammar, vocabulary, and idioms is not enough. Learning the ways in which the target language reflects the ideas, customs is also required. In other words, learning a language, in fact, is inseparable from learning its culture. It is important for Chinese teachers and students to realize the pragmatic differences of kinship terms in English and Chinese. Only can we expand and increase constantly language knowledge as well as culture knowledge, we will be able to use kinship terms appropriately and avoid pragmatic failures in communication.

\section{CONCLUSION}

As important carriers of culture, English and Chinese differ greatly. Kinship terms system is one of the typical differences. Chinese has more kinship terms in English, and they are much more complicated than those in English. Chinese kinship terms system is more complex with detailed classification, clear semantics, while English, on the contrary, its kinship terms system is relatively simple and generalized. Chinese kinship terms are characterized by arrangement in order of seniority in generation or in age. While English kinship terms are characterized by the glorification of individual at the expense of family relationship, so that names are widely used. In short, simplicity and complication, generality and specificity, are the basic contrastive features of kinship terms in English and Chinese.

Translation is an important means of cross-cultural communication. Kinship terms of Chinese and English can not be translated equivalently. So a correct understanding of kinship terms is directly conducive to the conversion between English and Chinese. An in-depth understanding of the Chinese and English kinship terms system can greatly promote 
cross-cultural communication more effectively.

Every nation has its own kinship terms, which reflects the social and psychological characteristics of different nationalities. English and Chinese kinship terms are different not only in system, but also in pragmatic meanings and ways of understanding. These differences are closely related to the cultural backgrounds of different kinship system.

To sum up, in this paper, the author mainly illustrates the differences between English and Chinese kinship terms, reveals the causes they result from, and introduces three translation methods. In a word, a comparison of Chinese and English kinship terms will help us better understand different cultures and promote cross-cultural communication.

\section{REFERENCES}

[1] Li Changbao. (2001). Studies of cultural differences between English and Chinese kinship terms. Journal of Sichuan International Studies University, 17(2), 93-96.

[2] Li Jincheng. (2009). An analysis on the influence of culture on the English translation of Chinese kinship terms. Journal of Xintai University, 24(4), 57-62.

[3] Li Yun. (2011). Analysis of cultural factors behind kinship terms between English and Chinese. Journal of Xinyang Agricultural College, 21(4), 101-103.

[4] Zhao Jing. (2007). On the differences between English and Chinese kinship appellations - from the Perspective of Semantics. Journal of Hunan University of Science and Engineering, 28(7), 109-111.

[5] Zhang Shifang. (2007). Diachronic evolution of Chinese appellations of relatives. Rehtoric Learning, 6, 45-49.

Chen Chen was born in Changzhi, China in 1992. He received his Bachelor's degree in literature from Harbin Normal University, China in 2015. His major field of study: history.

He is currently a postgraduate student in the School of Foreign Languages, Shanxi Normal University, Linfen, China. His research interests include applied linguistics and translation. 